\title{
Prismatic displacement of vision induces transient changes in the timing of eye-hand coordination
}

\author{
YVES ROSSETTI, KAZUO KOGA, and TADAAKI MANO \\ Nagoya University, Nagoya, Japan
}

\begin{abstract}
Eye-hand coordination was investigated during a task of finger pointing toward visual targets viewed through wedge prisms. Hand and eye latencies and movement times were identical during the control condition and at the end of prism exposure. A temporal reorganization of eye and hand movements was observed during the course of adaptation. During the earlier stage of prism exposure, the time gap between the end of the eye saccade and the onset of hand movement was increased from a control time of 23 to $68 \mathrm{msec}$. This suggests that a time-consuming process occurred during the early prism-exposure period. The evolution of this time gap was correlated with the evolution of pointing errors during the early stage of prism exposure, in such a way that both measures increased at the onset of prism exposure and decreased almost back to control values within about 10 trials. However, spatial error was not entirely corrected, even late in prism exposure when the temporal organization of eye and hand had returned to baseline. These data suggest that two different adaptive mechanisms were at work: a rather short-term mechanism, involved in normal coordination of spatially aligned eye and hand systems, and a long-term mechanism, responsible for remapping spatially misaligned systems. The former mechanism can be strategically employed to quickly optimize accuracy in a situation involving misalignment, but completely adaptive behavior must await the slower-acting latter mechanism to achieve longterm spatial alignment.
\end{abstract}

The human organism is able to adapt to many kinds of optical transformations of a visual scene. Since the end of the last century, a considerable amount of work has been performed on prism adaptation, especially on the locus of adaptation (see reviews in Koga, 1988; Kohler, 1962; Kornheiser, 1976; Welch, 1986). The different theories of prism adaptation can be classified into three main groups, based on the hypothesized nature of adaptation: arm proprioceptive change (Harris, 1963), central change in plurimodal coordination (Hardt, Held, \& Steinbach, 1971;

This work was supported by the Liaison Université-Industrie, Rayonnement International, Lyon, France, the French Ministry of Research and Technology and Human Frontiers Science Program to Y.R., and by the grant in aid for developmental scientific research (6381002) from the Ministry of Education, Science and Culture of Japan to K.K. The authors are pleased to acknowledge Takara Tashiro, of Osaka City University, for providing the prisms used in this experiment, Hirokazu Yoshimura, of Kanazawa City University, for valuable comments about the experimental design and procedure, Kenji Susami, of Chukyo University, Nagoya, for his skillful help in the experimental hardware design and construction, Marc Jeannerod, and Claude Prablanc, of INSERM, Lyon, Alan Hein, of MTT, and Karen Reinke of the University of Arizona, for thoughtful comments on the manuscript, and the voluntary subjects from the Department of Psychology, Nagoya University. We are especially indebted to an anonymous referee for detailed comments and corrections on a previous version of the manuscript. K. Koga and T. Mano are associated with the Space Medicine Experiment Center, Research Institute of Environmental Medicine, Nagoya University, Furo-cho, Chikusa-ku, Nagoya, Japan. Address correspondence and requests for reprints to Y. Rosetti, Vision et Motricité - INSERM U. 94, 16 Avenue du doyen Lépine, 69500 Bron, France (e-mail: rossetti@FRSUN12.bitnet).
Held, 1961; Kohler, 1955), and efferent change (e.g., Baily, 1972; review in Kornheiser, 1976). Then it was demonstrated that there is no single locus of adaptation (Harris, 1965; Putterman, Robert, \& Bregman, 1969; Welch, Choe, \& Heinrich, 1974). More recently, the idea of additivity of the different components of adaptation was developed and supported by experimental data (Ebenholtz, 1976; Redding \& Wallace, 1978; Templeton, Howard, \& Wilkinson, 1974; Wallace \& Redding, 1979; Wilkinson, 1971). In addition, the locus of adaptation may vary with cognitive factors (Redding \& Wallace, 1988). A recent theory of prism adaptation views the visuomotor system as a chain, in which visual inputs are processed within an eyehead system and proprioceptive inputs within an arm-head system (Redding \& Wallace, 1992). Eye-hand adaptation can thus result from the adaptation of one or both main components of this chain. Different subsystems can then be defined to face various experimental conditions.

Theories of prism adaptation are all based on the distribution and transfer of aftereffects observed at the removal of the prisms. The typical paradigm of prism adaptation is defined as "a comparison of performance on a criterion measure after prism exposure with performance measured before prism exposure" (Redding \& Wallace, 1992). Indeed, very little is known about the dynamic aspect of the adaptation phenomenon. In his extensive review, Kornheiser (1976) stated that the concept of prism adaptation as a dynamic process has not been adequately explored. Since then, very few attempts have 
been made in this direction (see Jacobson \& Goodale, 1989; Redding \& Wallace, 1992; Welch 1986). Because prism adaptation is typically a rearrangement of the eyehand coordination system, it is striking that no description of eye-hand coordination during the development of prism adaptation has yet been provided. In the present study, we focused on two aspects of eye-hand coordination: the spatial aspect, explored by the amount of adaptation, and the temporal aspect, concerned with the relative timing of the eye and arm movements.

Several authors have provided measures of adaptation as a function of time. Welch and Goldstein (1972) showed that after an initial rise observed at the first trial, pointing errors decreased down to the control level within about 4-6 trials. Similar results were obtained by others (Baily, 1972; Jacobson \& Goodale, 1989). Pointing errors are thus usually assumed to disappear completely within a few trials. However, using a similar procedure of terminal error feedback, Weiner, Hallett, and Funkenstein (1983) noticed that a pointing bias of about $15 \%$ persisted after 25 pointing trials. Devane (1968) showed that the decrease of pointing errors over time during the recovery from wedge prism adaptation was also asymptotic. In the case of adaptation of an automatic process to reversing prisms, Gonshor and Melvill-Jones (1976) reported that the functional recovery of vestibuloocular reflex (VOR) performance remained incomplete, even after long-term exposure.

Therefore, the first aim of the present study was to describe the course of pointing errors from the very first trials and to compare the errors made by the adapted eyehand system with those obtained during preexposure. In other words, our aim was to determine whether a number of exposure trials greater than usually reported would produce a complete suppression of pointing errors.

Because temporal parameters of eye-hand coordination have been shown to be sensitive to various experimental conditions (reviewed in Jeannerod, 1988, p. 44), one may expect these parameters to be altered by a modification of the eye-hand sensorimotor system, and to reflect some aspects of the actual mechanism operating during the development of prism adaptation. The study of the temporal pattern of eye-hand coordination during prism exposure addresses two sets of questions that are concerned with (1) the processes taking place during the beginning of the prism exposure, and (2) the comparison of the adapted state's performances to preexposure performances. Jacobson and Goodale (1989) reported that pointing movements performed under wedge prism exposure were transiently altered during the first reaching trials, and that the normal pattern of movements was reinstated after a few trials. In their experiment, hand-movement time and time to peak velocity (TPV) remained unchanged throughout the experiment, but hand-movement latency increased during the very first trials of the prism exposure. This result suggests that the temporal aspect of eye-hand coordination may be modified, at least during early exposure to prism displacement. Also using a visual rearrangement paradigm, Melvill-Jones, Guitton, and Berthoz (1988) studied the short-term changes in VOR after attempting visual tracking of a mirror-reversed image of the visual surround. They showed that the progressive reduction of VOR gain was preceded by a reorganization of eye movement involving saccadic components. They hypothesized that a substitutive mechanism took place, at least during the early adaptation of the VOR. Indeed, the incomplete functional adaptation of VOR observed after long-term exposure to visual distortion would also suggest that a substitutive mechanism rather than a pure adaptation is involved. Such a substitution may also be used in the case of voluntary arm movements. Modification of the temporal pattern of eye-hand coordination was thus investigated here, and a search for these possible modifications focused on the initial period of prism exposure and the adapted stage. Occurrence of any early basic modification would suggest that a new strategy of eye-hand coordination needs to be adopted to fulfill adaptation, in addition to the normal coordination.

The present experiment was designed to investigate the spatial and temporal aspects of eye-hand coordination during prism adaptation. Two main questions were addressed:

1. Do the eye-hand coordination parameters exhibit a transient alteration during the initial stage of prism exposure, or does this alteration slowly develop and continue throughout prism exposure? In both cases, if a difference in eye-hand timing is observed, it would suggest that the development of adaptation or the adaptation itself implies a change in the sensorimotor strategy to fulfill pointing accuracy. It would also argue for the implication of additional visuomotor processing during the corresponding period. Such an additional processing time may be revealed by an increase of hand-movement latency, as suggested by Jacobson and Goodale (1989).

2 . What is the time course of the pointing bias measured during a large number of pointing trials under prism exposure? Evolution of this bias may also be used to interpret the possible alterations of the temporal parameters of eye-hand coordination. ${ }^{1}$

\section{METHOD}

\section{Subjects}

The subjects were 9 right-handed, graduate male students (23-31 years old), with normal visual acuity, who had not previously engaged in a prism-adaptation experiment. They sat in front of a horizontal table $(120 \times 60 \mathrm{~m})$. The head was restrained by a bite board in order to prevent the adaptive deviation of head posture (Harris, 1965; Templeton et al., 1974). The position of the head was adjusted so that the subject's hand was out of his visual field when his finger was on the starting point. This procedure is supposed to reduce the cross-recalibration of visual and proprioceptive maps (Prablanc, Echallier, Komilis, \& Jeannerod, 1979b; Jeannerod, 1991), and thus is likely to slow down the development of adaptation. The subject held a buttonpress in his left hand, which was kept under the table, and used his right finger for the pointing task.

\footnotetext{
Apparatus

Goggles. The subjects wore binocular goggles throughout the experiment. Large acrylic wedge prisms $(6.0 \times 6.5 \mathrm{~cm})$ were fixed into
} 
the frame, with the base on the left side. During the prism exposure, the subjects were exposed to a $10^{\circ}$ shift of the visual axis. During the control condition, a removable identical prism was fixed into the goggles in front of each previously described prism, but with the base on the right side. The resulting deviation of the visual axis was $0^{\circ}$. By this procedure, the visual angle $\left(85^{\circ}\right.$ monocular and $110^{\circ}$ binocular in the horizontal dimension, and $70^{\circ}$ in the vertical dimension), the opacity effect of the acrylic, and the subjective feelings of the subjects were similar during the control and prism-exposure conditions. This procedure was designed to minimize the situational effect described by Kohler (1964). The weight of the goggles varied from $230 \mathrm{~g}$ (prism condition) to $330 \mathrm{~g}$ (control condition).

Experimental table and stimulus presentation. The finger starting point was set close to the chest, aligned with the body's sagittal axis, and was indicated by a tactile cue on the table. A fixation point (green LED) was presented on the table, $57 \mathrm{~cm}$ in front of the starting point. The targets were five red LEDs placed radially at $0.43 \mathrm{~m}$ from the starting point and positioned $-17.0^{\circ},-8.5^{\circ}, 0.0^{\circ},+8.5^{\circ}$, and $+17.0^{\circ}$ left to right relative to the sagittal plane. The light intensity provided by the fixation point was $1.2 \mathrm{~cd} / \mathrm{m}^{2}$ and that of the target LEDs was $2.9 \mathrm{~cd} / \mathrm{m}^{2}$. The ambient light was $0.1 \mathrm{~cd} / \mathrm{m}^{2}$. All the LEDs were driven through the parallel outputs of a computer (EPSON PC-286 LE), which provided a random presentation of the five target positions.

Eye-movement recordings. Horizontal and vertical eye movements were recorded by an electrooculograph with five $\mathrm{Ag}-\mathrm{AgCl}$ skin surface electrodes (Nihon Koden) connected to a two-channel amplifier (Nihon Koden Nystagmograph). EOG calibration was performed by requiring the subjects to fixate prepositioned points on a vertical blackboard. The mean spatial resolution of this method was $1.4^{\circ}$ for the horizontal component and $4.3^{\circ}$ for the vertical component.

Finger tracking. Two-dimensional movements of the arm were recorded by a TV camera (ELMO 202C) placed $1.57 \mathrm{~m}$ above the center of the table. An LED was affixed to the tip of a subject's index finger and lit during the experiment. This point was followed by an $X-Y$ tracker (Hamamatsu Photonics $\mathrm{C} 1000$ ). Recording started at the time of target presentation, so that hand-movement latency could be calculated for each movement. The absolute spatial resolution of the tracker was $5.5 \mathrm{~mm}$.

\section{Procedure}

Target pointings were grouped into blocks of 5 trials ( 1 trial per target position). The experiment consisted of 26 pointing blocks: 10 blocks ( 50 trials) under the control condition and 16 blocks ( 80 trials) under the prism-exposure condition.

Each pointing trial was organized as follows. The subject was instructed to keep his right index finger on the starting point and wait for an auditory signal. The trial was then self-initiated by pressing the button held in the left hand, whereupon the fixation LED was extinguished and a target LED was immediately illuminated. The subject was then required to hit the target as quickly and as accurately as possible (movement time around $200 \mathrm{msec}$ ), and to avoid final correction of the trajectories. Thus, the subject's movements could be considered as nearly ballistic, and visual guidance as being maximally reduced. Visual comparison of the finger's final position and target location was available at the end of the trial. The subject then brought his finger back to the starting point and the next trial began.

\section{Data Acquisition and Analysis}

Once a trial started, data sampling was run for $1 \mathrm{sec}$. Horizontal and vertical EOG signals and hand-position tracking were $A / D$ converted (NEC PC 9801/VX21, and Canopus ADX98, eight channels) and fed to the data acquisition software. The sample frequency was $100 \mathrm{~Hz}$ for EOG and $60 \mathrm{~Hz}$ for hand-position tracking.
All the data were filtered through a $30-\mathrm{Hz}$ second-order lowpass Butterworth filter. The first derivative of the pointing-data file was filtered at $20 \mathrm{~Hz}$ and then used to determine the latencies and duration of eye and hand movements. The thresholds used for this automatic process were determined empirically for every subject after manual examination of at least 10 files, and then were set constant for each subject.

Angular pointing error was measured with respect to sagittal body axis. For each trial, the time to peak velocity, the time interval between eye-movement onset and hand-movement latency, and the time gap between the end of the eye saccade and the hand-movement onset were computed. The few trials for which the eye latency was longer than the hand latency were not taken into account in the analysis of time parameters. The mean of each parameter was computed for each block, thus including 45 ( 9 subjects $\times 5$ LEDs) pointing trials.

Stages of analysis. According to a preliminary analysis (Rossetti, Koga, Susami, \& Mano, 1991), which is summarized below, three different stages were considered in the experiment. After about 10-15 pointing trials in the control, the subjects became familiar with the task, so that the angular error values and movement parameters stabilized. The proper control stage included Blocks 4-10 and provided a baseline for normal eye-hand coordination. In addition, two different stages were distinguished within the prism-exposure condition. An earlier stage of prism exposure (Blocks 11-12) was distinguished from a later stage (Blocks 18-26). The earlier stage corresponded to the rapid decrease of pointing errors, and the later stage corresponded to a stabilized level of error. Spatial and temporal measures of pointing performances were compared among these three stages. The mean values pooled over the 9 subjects were computed for each of the three stages of the experiment. The total number of trials included in these means was $n=315$ (seven blocks) for the control condition, $n=90$ (two blocks) for the early stage, and $n=405$ (nine blocks) for the later stage of the prism-exposure condition.

An analysis of the results was performed for (1) comparison of the status of eye-hand coordination observed during the control and the later stage of prism exposure, and (2) investigation of the early effects of prism exposure on eye-hand coordination. Statistical differences between the three stages of the experiment were tested for all parameters by repeated measures analysis of variance (ANOVAs) (Snedecor \& Cochran, 1984); individual means over blocks were used. The significance of the trends observed over the trials during the earlier stage of exposure was tested by linear regression statistics on block means over subjects for control and later stage, and on trial means over subjects for the earlier stage of prism adaptation.

\section{RESULTS}

Because the pace of target presentation depended upon a subject's pressing the button, the total duration of the experiment varied from 40 to $47 \mathrm{~min}$ among the 9 subjects.

\section{Pointing Errors}

During the control, the mean ( $\pm S D$ ) angular error computed for the 9 subjects was $.9^{\circ} \pm .32^{\circ}$. During the earlier stage of prism exposure, the angular bias decreased from an average of $9.9^{\circ} \pm 4.5^{\circ}$ on Trial 1 to less than $6^{\circ}$ for Trials $3-7$, with a further drop to between $3^{\circ}$ and $4^{\circ}$ for Trials 8-10 (see Figure 1). Values below $3.0^{\circ}$ were observed from Trial 12 (middle Block 3), and values below $2.0^{\circ}$ from Trial 21 (early in Block 5 ). The mean pointing bias was $5.8^{\circ} \pm 2.63^{\circ}$ in the earlier stage, and stabilized 


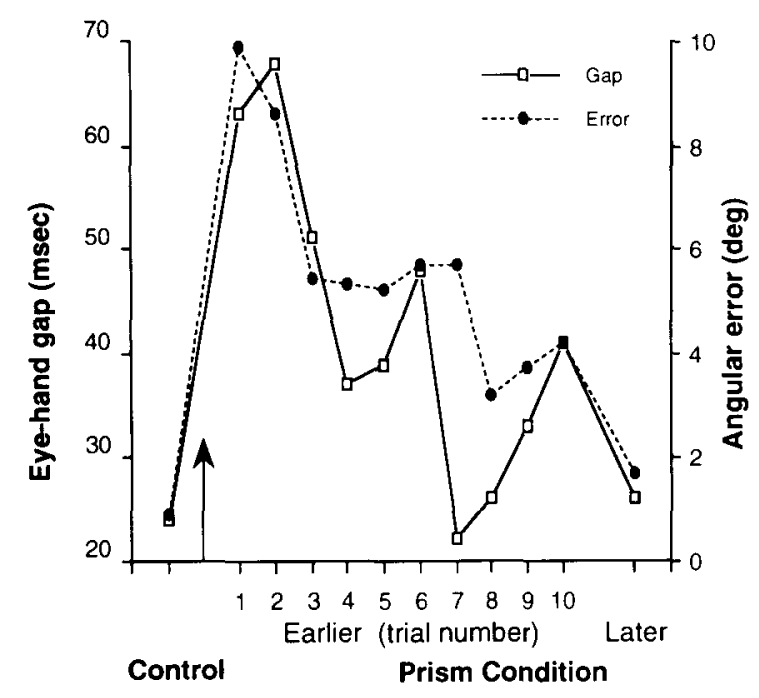

Figure 1. Temporal course of eye-hand gap and pointing errors through the 10 trials of the earlier stage of prism exposure, compared with the mean values of the control condition and later prism exposure. The vertical arrow indicates the onset of the prismexposure condition. These two parameters show similar changes along the first pointing trials.

just short of baseline in the later stage, averaging $1.7^{\circ} \pm$ $.42^{\circ}$. A one-way repeated measures ANOVA computed between the three stages was highly significant $[F(2,26)=$ $24.32, p<.0001$ ], and a post hoc Scheffé's test showed a statistically significant difference between the earlier exposure stage and the other two. It is interesting that the slight difference between the control value and the later prism-exposure condition (about $8 \%$ of the prism-induced visual shift) also reached statistical significance.

\section{Qualitative Description of Temporal Parameters}

From Block 4 to Block 10 (control), temporal parameters remained stable. During the first pointing trial of the prism exposure, the eye-movement temporal parameters remained unchanged, whereas the hand latency was increased by about $40 \mathrm{msec}$ and hand-movement time by about $30 \mathrm{msec}$ (see Figure 2). During the second and third trials, the eye latency was slightly reduced; other eyemovement parameters were unchanged. After these first trials, the temporal parameters progressively returned to their control values. As a result, the time gap between the end of the saccade and the onset of the hand movement increased up to $68 \mathrm{msec}$ during the second trial and then progressively decreased back to control values within about 7 to 10 trials (Figure 1).

\section{Eye-Movement Timing}

The eye-movement latency was stable during the control stage, averaging $( \pm S D) 225 \pm 35 \mathrm{msec}$ (see Table 1). On the average, eye latency during the earlier stage of prism exposure $(218 \pm 40 \mathrm{msec})$ was not different from baseline, but as can be seen in Figure 2, eye latency de- creased by $30 \mathrm{msec}$ from Trial $1(226 \mathrm{msec})$ to Trial 3 $(196 \mathrm{msec})$ and then rose back up to a near-baseline value of $217 \mathrm{msec}$ by the last trial of the early stage of prism exposure. Eye latency was stable and near baseline during the later stage of prism exposure, averaging $225 \mathrm{msec}$ $( \pm 32 \mathrm{msec}$ ). Saccade duration (eye-movement time, or eye MT) and eye TPV tended to be stable in all three stages and were not largely different from baseline level (see Table 1). The one-way repeated measures ANOVA computed between the three stages did not reach statistical significance for either of these three parameters $[F \mathrm{~s}(2,26)<1.2$, n.s. $]$. Thus, the total time between target onset and target fixation (latency + MT) or "eyereaching time" was only slightly less for the early stage (315 msec) compared with the control $(326 \mathrm{msec})$ and later (324 msec) stages, reflecting the shortening of eye latency during the initial trials of the early stage of prism exposure (see Figure 2).

\section{Hand-Movement Timing}

The hand-movement latency was stable during the control stage, averaging $( \pm S D) 349 \mathrm{msec}( \pm 30 \mathrm{msec}$ ) (see Table 1). On the average, hand latency during the early stage was not largely different from baseline but, as can be seen in Figure 2, hand latency increased up to $384 \mathrm{msec}$ $( \pm 23 \mathrm{msec})$ for the first trial and then decreased back to the baseline level as early as Trial 3. Hand latency was stable at near-baseline levels in all stages $[F(2,26)=.508$, n.s.) (see Table 1). Thus, the total time between target onset and completion of the pointing movement (latency

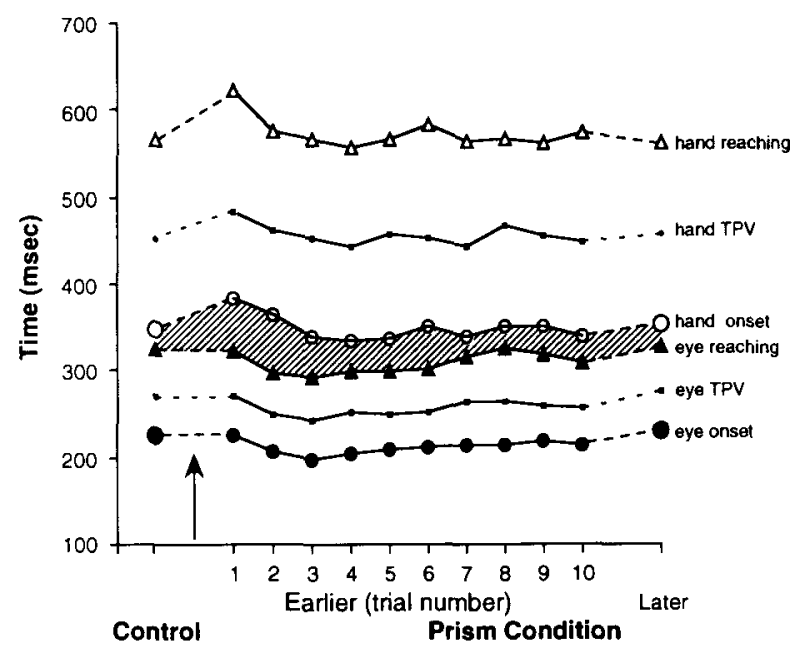

Figure 2. Change in eye and hand temporal parameters through the 10 trials of the early prism-exposure condition, compared with values of the control condition and later prism exposure. True times of events are expressed in milliseconds from target presentation, in such a way as to respect the actual chronology of movement onset, time to peak velocity (TPV), and movement end. The vertical arrow indicates the onset of prism exposure. The eye-hand gap, as indicated by the dark area, was increased during the first trials of the prism exposure, whereas total reaching time was modified only during the first trial. 
Table 1

Means $(M)$ and Standard Deviations $(S D)$ in Milliseconds for the 9 Subjects During the Control Condition (Pooled Blocks 4-10), Earlier Stage (Pooled Blocks 11 and 12), and Later Stage (Pooled Blocks 18-26) of the Prism-Exposure Condition

\begin{tabular}{|c|c|c|c|c|c|c|}
\hline \multirow[b]{3}{*}{ Parameters } & \multirow{2}{*}{\multicolumn{2}{|c|}{ Control }} & \multicolumn{4}{|c|}{ Prism Condition } \\
\hline & & & \multicolumn{2}{|c|}{ Earlier } & \multicolumn{2}{|c|}{ Later } \\
\hline & $M$ & $S D$ & $M$ & $S D$ & $M$ & $S D$ \\
\hline Eye latency & 225 & 35 & 218 & 40 & 225 & 32 \\
\hline Eye TPV & 45 & 4.2 & 44 & 5.2 & 44 & 5.5 \\
\hline Eye MT & 99 & 8.4 & 97 & 9.9 & 99 & 9.7 \\
\hline Eye reach & 326 & & 315 & & 324 & \\
\hline Hand latency & 349 & 30 & 359 & 61 & 352 & 41 \\
\hline Hand TPV & 116 & 20 & $107 *$ & 26 & $106^{*}$ & 20 \\
\hline Hand DT $(\%)$ & 47 & & 52 & & 51 & \\
\hline Hand MT & 219 & 42 & 222 & 37 & 215 & 41 \\
\hline Hand reach & 568 & & 581 & & 567 & \\
\hline Hand latency/Eye latency & 122 & 47 & $141 \dagger$ & 49 & 127 & 35 \\
\hline Eye-Hand gap & 23 & 46 & $44 \dagger$ & 56 & 28 & 35 \\
\hline Errors (degrees) & 0.9 & 0.3 & $5.8 \ddagger$ & 2.6 & $1.7 \ddagger$ & 0.8 \\
\hline
\end{tabular}

Note-TPV $=$ time to peak velocity; $\mathrm{MT}=$ movement time; $\mathrm{DT}=$ deceleration time. ${ }^{*} p<.05 . \quad \neq p<.005 . \quad \neq p<.0001$.

+ MT) or "hand-reaching time" was only slightly longer for the earlier stage $(581 \mathrm{msec})$ than for the control $(568 \mathrm{msec})$ and later $(567 \mathrm{msec})$ stages $[F(2,26)=.124$, n.s.], reflecting the lengthening of hand latency during the initial trials of the earlier stage of prism exposure. Hand TPV averaged less for both the early $(107 \mathrm{msec})$ and later $(106 \mathrm{msec})$ stages of prism exposure compared with baseline $(116 \mathrm{msec})$. Thus, a larger percentage of MT was spent in deceleration time for the early (52\%) and later $(51 \%)$ stages of prism exposure than during baseline $(47 \%)$. The one-way repeated measures ANOVA computed between the three stages reached statistical significance only for TPV $[F(2,26)=5.51, p<.02$; Scheffé's post hoc test showed a higher value for the control relative to the other two stages].

\section{Eye-Hand Timing Differences}

The time interval between completion of the eye movement and onset of the hand movement (hand latency-eyereaching time) or "eye-hand gap"' was, on the average, longer for the earlier stage $(44 \pm 56 \mathrm{msec})$ than for either the baseline $(23 \pm 46 \mathrm{msec})$ or later stage $(28 \pm 35-\mathrm{msec})$ $[F(2,26)=7.61, p<.005]$ (see Figure 1 and Table 1 ). The value obtained for the earlier stage of prism exposure was significantly higher than for the other two stages. This pattern of change in gap duration through the three stages of the experiment was found for the five target positions and was observed in 7 of the 9 subjects. The other 2 subjects showed only the increase during earlier exposure with respect to control, and then, again, a mean increase of about $25 \mathrm{msec}$ from earlier to later prism exposure. The mean results were computed for all 9 subjects. The largest value $(68 \pm 50 \mathrm{msec})$ appeared for the second trial of the prism condition (Figure 1), and was significantly higher than the control value $(p<.0001)$. The lowest values of the gap between the end of the eye saccade and hand-movement onset were observed for the cen- tral target, but there was no further obvious relationship between target position and duration of the gap.

As shown in Table 1, the time interval between eyemovement onset and hand-movement onset (hand latencyeye latency) was, on the average, longer for the early stage $(141 \pm 49 \mathrm{msec})$ than for the baseline $(122 \pm 47 \mathrm{msec})$ and later $(127 \pm 35 \mathrm{msec})$ stages $[F(2,26)=7.61, p<.005]$ (Table 1). These differences reached statistical significance $[F(2,26)=4.21, p<.05]$. The highest value of the time interval between eye- and hand-movement onsets $(159 \pm 50 \mathrm{msec})$ was found for the second trial of the earlier stage of prism exposure.

\section{Time Courses Observed During \\ Earlier Stage of Prism Exposure}

The changes in pointing error and eye-hand gap over trials during the earlier stage of prism exposure are presented in Figure 1. The decrease of angular error versus time observed over the 10 trials of the earlier stage of prism exposure was fitted with a linear regression $(y=$ $-5.8 x+8.9$ ), which reached high statistical significance $(R=.836, p<.003)$. A similar fitting was processed for all other temporal parameters, and statistical significance was reached only for the eye-hand gap $(R=.744$, $p<.02$ ) and for the time interval between eye- and handmovement onsets $(R=.675, p<.05)$.

\section{Correlation Between Spatial and Temporal Parameters}

As shown in Figure 3, linear regression of terminal error and eye-hand gap averaged over subjects for each stage revealed a significant negative correlation across block means during control $(y=1.70-.03 x, R=.754$, $p<.005$ ), and a significant positive correlation across trial means during the earlier stage of prism exposure $(y=.90+.11 x, R=.802, p<.005)$, but no relationship across block means during the later stage of prism

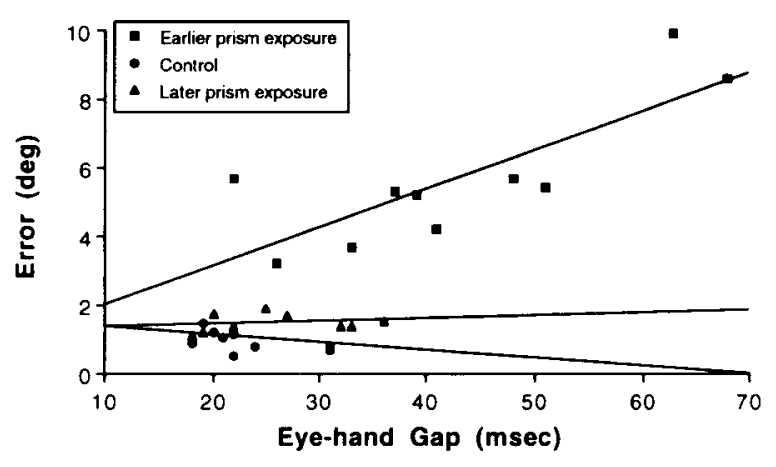

Figure 3. Regression observed between eye-hand gap (in milliseconds) and pointing error (in degrees of arc), according to the stage of the experiment. Values shown for the earlier stage are trial means across subjects ( 9 trials per point), and block means across subjects (45 trials per point) for control and later stage. The best-fitting line was given by $y=1.70+.03 x(R=.530, p<.05)$ for the control condition, $y=.90+.11 x(R=.802, p<.005)$ for the earlier stage of prism exposure, and $y=1.27+.008 x(R=.197$, n.s.) for the later stage of prism exposure. 
exposure. In the earlier stage of prism exposure, the only significant relationships showed that the pointing bias was also related to the time interval between eye- and handmovement onsets $(R=.796, p<.01)$ and hand-movement time $(R=.275, p<.01)$. As reported previously, this relationship between pointing errors and hand-movement time was negative $(y=12.24-.03 x)$.

\section{DISCUSSION}

\section{Pointing Errors}

The pointing errors observed during the control condition were consistent with Prablanc et al.'s (1979b) study. In their study, the constant pointing error increased from $0.3^{\circ}$ to about $1.1^{\circ}$ for a $12^{\circ}$ target when vision of the static hand prior to movement was removed, as was the case in the present experiment. The present angular bias observed for the first pointing trial of the prism-exposure condition was about $10^{\circ}$. This initial pointing bias was similar to the prismatic displacement of the visual field.

In the present experiment, pointing errors reached a plateau near control values around Trial 25 of the prismexposure condition. In other experiments, the use of $11^{\circ}$ and $15^{\circ}$ deviated vision, $3 \mathrm{~min}$ (Harris, 1963), or 3 to 14 trials (Tashiro, 1972) was enough to get pointing performance to reach the control level. Welch and Goldstein (1972) also obtained error-reduction curves that reached near baseline in less than 10 trials. In a study using terminal feedback of pointing errors, the same decrease in pointing errors was observed when fast or slow movements were performed during the exposure period (Baily, 1972). In both cases, errors reached values close to zero after about 10 trials, although a slight bias seemed to persist up to about Trial 25. Weiner et al. (1983) also observed a pointing bias persisting up to at least 25 trials. In the present experiment, although pointing errors observed during the later stage of prism exposure (Trials 40-80) were considerably reduced when compared with the earlier stage of prism exposure, they remained higher than the control baseline. To our knowledge, such a long-lasting effect of wedge prism has not been mentioned in the literature. This may be explained by our prism-exposure procedure, which was designed to slow down the development of the adaptation, or by the absence of statistics aimed at detecting small differences observed in other studies. Although the prism-exposure conditions used in this experiment were designed to slow down the adaptation rate, this observation suggests that one should be careful before interpreting an apparent resolution of errors.

\section{Timing}

The temporal patterns of eye-hand coordination during the later stage of prism exposure were identical to those observed during the control stage. This indicates that no additional time-consuming process seemed to be involved in the task explored after adaptation had developed, and suggests that the adapted state of eye-hand coordination may be similar to the normal one, as far as timing is concerned.
Eye-movement parameters. Latency and duration of eye saccades were within the usual range (Biguer, Jeannerod, \& Prablanc, 1982; Fisher \& Rogal, 1986; Prablanc, Echallier, Jeannerod, \& Komilis, 1979a). A decrease in eye latency was reported by Fisk and Goodale (1989) when instructions given to their subjects emphasized pointingmovement accuracy rather than speed. The difference observed between these two conditions ( $35 \mathrm{msec}$ ) was similar to the highest decrease reported here $(-30 \mathrm{msec}$ for the third trial of the prism condition).

Hand-movement parameters. The mean latency of hand movement observed during the present control condition ( $349 \mathrm{msec}$ ) was similar to that previously reported: $340 \mathrm{msec}$ for a $10^{\circ}$ target in a fixed-head condition (e.g., Prablanc et al., 1979a). In the present experiment, this latency was not significantly increased during the prism exposure, whereas in another experiment, Tashiro (1972) found the finger-pointing latency to be lengthened by about $70 \mathrm{msec}$ when vision was prismatically displaced. In this latter experiment however, no time constraints were imposed on the subjects. Jacobson and Goodale (1989) also qualitatively reported an increase of hand latency during the first pointing movements made under prism exposure. Hand-movement duration used in the present experiment (about $220 \mathrm{msec}$ ), although faster than is usually used in pointing tasks (e.g., Prablanc et al., 1979a), was similar to that of the fast movements $(225 \mathrm{msec})$ used by Baily (1972).

Eye-hand timing differences. In the present experiment, the time gap between the end of the saccade and the hand-movement onset (eye-hand gap) was primarily described, because statistical analysis showed this parameter to be more affected than the others. The functional significance of this gap is the duration of foveal information available before the onset of hand movement. However, this parameter is not described in most studies, and comparison has to refer to the difference between the two latencies. The mean time interval between eye- and handmovement onsets observed in the present experiment (122 msec during the control) is similar to the value reported by Prablanc, Pelison, and Goodale (1986) in both a visual-feedback condition $(114 \mathrm{msec})$ and a withoutvisual-feedback condition $(127 \mathrm{msec})$. In the present experiment, the time interval between eye- and handmovement onsets increased up to $140 \mathrm{msec}$ during earlier prism exposure. When orienting toward a unique $10^{\circ}$ target, Fisher and Rogal (1986) found an even smaller time interval between eye- and hand-movement onset $(60 \mathrm{msec})$. The differential effect of prism exposure on eye and hand latencies indicates that finger and arm latencies can be affected in different ways, and thus may also support the hypothesis of separate, even if parallel, activation of the eye and arm motor systems (for a discussion of this point, see Jeannerod, 1988, p. 45).

\section{General Discussion}

It was shown here that no difference in the timing of the eye-hand system was observed between the control and the later stage of the prism exposure. By contrast, 
the pointing bias still remained significantly higher during the later stage of prism exposure than during the control. The fact that terminal error was not completely removed, even late after the temporal organization of eye and hand movements had returned back to baseline, suggests that two different adaptive mechanisms were involved in the reduction of errors. The fine-tuning of the later adaptation would not require an overt alteration of eye-hand coordination, and thus may be similar to the mechanism involved in normal conditions. Hypotheses concerning the mechanism involved in reducing the error during the earlier stage of prism exposure will be discussed below.

The main significant result of the present experiment is an increase of the time gap between the end of the eye saccade and the hand-movement onset observed during the earlier stage of the prism-exposure condition. As seen in Figure 1, this eye-hand gap was increased at the onset of the prism condition and then rapidly decreased, tightly following the same time course as the pointing error. Similarly, Fisk and Goodale (1989) showed that the difference between eye and hand latencies rose from about $50 \mathrm{msec}$ for speeded movements to about $65 \mathrm{msec}$ when both speed and accuracy were required, and up to about $100 \mathrm{msec}$ when only accuracy was required. As stressed by Carnahan and Marteniuk (1991), the amount of time by which the eyes precede the finger to the target might be one factor that contributes to movement accuracy. It has been demonstrated that foveation (foveal capture of the target) provides more salient gaze-position information, which can be used to guide the arm (Prablanc et al., 1979a, 1986). A requirement for accuracy would then imply an alteration of the eye-hand timing in such a way as to increase the available foveation time before the hand starts.

The increase of this time may be obtained in several ways. First, if there is no time constraint, the visuomotor system can increase all elementary components of the reaching behavior. This was the case in the experiment by Carnahan and Marteniuk (1991), in which the total reaching time increased from about $570 \mathrm{msec}$ for speeded movements to about $980 \mathrm{msec}(+72 \%)$ for accurate movements toward a $26^{\circ}$ target. In this latter experiment, all temporal parameters increased in parallel-both eye latency and eye-movement time by about $17 \%$, hand latency by about $46 \%$, and hand-movement time by about $104 \%$ (percentage values computed from the absolute values provided in their paper). This resulted in a dramatic increase (about five times) in the time interval between eye- and hand-movement onsets.

Second, if the time allocated to the reaching task remains constant, the visuomotor system has to redistribute the allocated time among the different components of the reaching task. Fisk and Goodale (1989) provided such an example, in which the total reaching time toward $10^{\circ}$ and $20^{\circ}$ targets only varied between about $960 \mathrm{msec}$ for a speed/accuracy requirement and about $980 \mathrm{msec}$ for an accuracy requirement. In this latter case, the eye latency was decreased by about $35 \mathrm{msec}(11 \%)$, whereas the hand latency was kept constant (about $360 \mathrm{msec}$ ). This resulted in an increase of the time interval between eye and hand latency from about 65 to $100 \mathrm{msec}(+65 \%$ ) (percentage values computed from the absolute values provided in their paper). Although adequate time was available for computing visuomotor transformation in this latter experiment, it is striking that an increase of the gap still occurred. This could suggest that the gap increase is not strategy dependent, but relies instead on a more basic mechanism.

In both of these cases, the visuomotor system was reorganized in such a way as to increase the time delay between eye and hand latencies in response to increased accuracy constraints. This preferential increase of the difference between eye and hand timing suggests that this delay is of primary importance. Indeed, in the present experiment, this gap was more significantly correlated with the course of the pointing bias. This is consistent with Prablanc et al.'s (1986) hypothesis that the duration of foveation preceding hand-movement onset is the crucial parameter. According to Fleisher (1989) and Abrams (1992), this increase of eye-hand gap, which measures foveation time before hand-movement onset, would allow for an increased number of arm trajectory corrections, and thus would improve the pointing accuracy. Previous studies reported an increase of the finger-pointing latency under the prism-exposure condition that may increase foveation time before movement onset, but did not describe the eyemovement parameters (Jacobson \& Goodale, 1989; Tashiro, 1972). In the present experiment, the need for trajectory updating was dramatically increased by the introduction of prisms, and this may have induced the increase in eyehand gap. Because the total reaching time was kept constant throughout the experiment, the visuomotor system had to optimize the relative timing of its components without altering the total pointing time, as in Fisk and Goodale's (1989) experiment. The reorganization of the timing also occurred in the arm movement. The reduction in hand TPV during prism exposure, which increases the relative deceleration time, is another way to improve pointing accuracy - a result that has been previously reported (see Jeannerod, 1988).

Although eye-hand gap and errors followed the same evolution over trials (Figure 3), the relationship between these two parameters was opposite to that observed during the control stage, to that described in Vercher, Prablanc, Magenes, and Gauthier (1992), and to that expected from other experiments (Carnahan \& Marteniuk, 1991; Fisk \& Goodale, 1989). It cannot be assumed that prism exposure induces an inversion of the causal relationship between the duration of foveation and accuracy. Rather, pointing error and eye-hand gap may be increased by the prism introduction, or an increase of the eye-hand gap may be required, as long as the prism-induced bias is not compensated. 
The question remains as to whether the increase of the time interval between the eye and the hand was specific to the visual transformation applied in the present experiment, or simply reflected a general feature of the eyehand system when it is faced with an increased requirement for accuracy. As with the observed pointing errors, the increase of the eye-hand gap may have resulted from the prism-induced visual-proprioceptive discrepancy. Accordingly, two hypotheses can be proposed. It may first be suggested that the observed eye-hand gap reflects the development of the adaptation itself. But there is no obvious reason why only the eye-hand gap would be modified by this process. Recalibration of the visual system or the arm proprioception would be more likely to occur during simultaneous exposure; that is, during or after the movement. The second hypothesis is that the gap reflects the time spent by a substitute of the adaptation. When there was a discrepancy between vision and proprioception (e.g., at the begining of the prism-exposure condition), the only way to reach a target accurately was to change the relation between visual inputs and motor outputs; that is, to act at the level of visuomotor transformations. Baily's (1972) results suggest that prism exposure with rapid hand movement is mostly achieved by changes in the motor efference rather than proprioceptive afference. Similar values of hand-movement time were used in the present experiment. Therefore, it may be hypothesized that the observed increase in gap may reflect the time spent by the sensorimotor system in specifying the updated motor efferences from the visual information.

The literature regarding visual rearrangement provides several hypotheses to account for the initial reduction of errors found here. Welch reviewed three immediate responses to the prismatic displacement, which allow a corrected behavior before the adaptation is accomplished (Welch, 1986; Welch \& Warren, 1980). Deliberate corrective responses, immediate correction, and intersensory bias effect are processes that are different from active adaptation, which can resolve the prism-induced visuoproprioceptive discrepancy. One of these responses might require an increase of the hand latency.

First, the immediate-correction effect is assumed to take place in a structured environment (Melamed, Beckett, \& Wallace, 1978; Rock, Goldberg, \& Mack, 1966; Welch, 1986). This was not the case in the present experiment, as the only observed environment consisted of the uniform black surfaces of the table and the curtain facing the subject. However, movements were performed under dim light, which could allow the immediate-correction effect to occur (Wallace, Melamed, \& Cohen, 1973). Although this effect is assumed to be immediate, no description of its evolution in time is available; it could also contribute to the initial drop in pointing errors during the first trials. The observed eye-hand gap might reflect the time necessary for this process to occur.

Second, the present increase of eye-hand gap may be due to the prism-induced intersensory bias. As a matter of fact, this bias is known to decrease while adaptation is produced (Welch \& Warren, 1980; Welch, Widawski, Harrington, \& Warren, 1979); a similar decrease was observed for the eye-hand gap here. Increase of the gap would be produced by the correction of the intersensory bias at the level of the visuomotor transformation.

Third, let us consider the issue of a deliberate corrective response. Before doing this, some consideration of terminology is required. We will intentionally avoid a discussion of conscious correction here, because the contribution of awareness to learning is a matter of controversy (e.g., Bedford, 1993). Awareness is usually considered unessential for perceptual learning. Indeed, prism adaptation is known to occur even without any awareness of the visual transformation (Jacobson \& Goodale, 1989). Similarly, cognitive learning may take place without conscious awareness of the task performed (Kihlstrom, Barnhardt, \& Tataryn, 1992). In the present experiment, the terminal feedback error provided to the subject may have been a cognitive cue that was probably used by the subject. Whether this was performed consciously or not remains unclear and may not be answered here. In any case, a time delay shorter than $50 \mathrm{msec}$ would be too short to allow a deliberate mental corrective translation of the visual scene. Although no data about the timing of mental translation is available, the usual delay reported for mental rotation of visual patterns is about $450 \mathrm{msec}$ (Shepard \& Metzler, 1971). Georgopoulos and Massey (1987) performed an experiment in which a subject was required to point at a given angle away from a presented target. When pointing $5^{\circ}-15^{\circ}$ away from the target, the mean achieved angle ranged from $16^{\circ}$ to $30^{\circ}$, and the hand-movement latency was increased by about $150 \mathrm{msec}$. This additional delay was considered to include both mental rotation time and a remaining $80 \mathrm{msec}$, which remained unexplained. This latter duration is very similar to the increase of the eye-hand gap reported here, and may correspond to the involvement of an additional loop for the updating of movement parameters. A role for the olivo-cerebellar system in the rapid improvement of pointing errors under prism exposure has already been suggested by observations of lesioned animals (Baizer \& Glickstein, 1973) and brain-damaged humans (Thach, 1991, personal communication; Weiner et al., 1983; Welch \& Goldstein, 1972). This anatomical system may be responsible for an increase of the eye-hand gap.

The present experiment provided a description of eyehand timing during wedge prism exposure. It was shown that the time gap between the end of the eye saccade and the onset of the hand movement was increased during the first pointing movements performed under prism exposure. However, this gap and the entire eye-hand timing were similar under the control and late-exposure conditions. The increase of the eye-hand gap reflects a transient change in the reaching strategy, which may be involved in reducing the prism-induced pointing bias. Further experiments are required to investigate whether 
this strategy serves a specific function in the case of prism adaptation, or only reflects a more general effect of accuracy constraint on the visuomotor system.

\section{REFERENCES}

Abrams, R. A. (1992). Coordination of eye and hand for aimed limb movements. In L. Proteau \& D. Elliott (Eds.), Vision and motor control (pp. 129-152). Amsterdam: Elsevier.

BAILY, J. S. (1972). Adaptation to prisms: Do proprioceptive changes mediate adapted behaviour with ballistic arm movements? Quarterly Journal of Experimental Psychology, 24, 8-20.

Baizer, J. S., \& Glickstein, M. (1973). Role of cerebellum in prism adaptation. Journal of Physiology, 236, 35P-36P.

BEDFORD, F. L. (1993). Perceptual and cognitive spatial learning. Joumal of Experimental Psychology: Human Perception \& Performance, 19, 517-530.

Biguer, B., Jeannerod, M., \& Prablanc, C. (1982). The coordination of eye, head, and arm movements during reaching at a single visual target. Experimental Brain Research, 46, 301-304.

Carnahan, H., \& Marteniuk, R. G. (1991). The temporal organization of hand, eye, and head movements during reaching and pointing. Journal of Motor Behavior, 23, 109-119.

Devane, J. R. (1968). Proaction in the recovery from practice under visual displacement. Perceptual \& Motor Skills, 27, 411-416.

Ebenholtz, S. M. (1976). Additivity of aftereffects of maintained head and eye rotations: An alternative to recalibration. Perception \& Psychophysics, 19, 113-116.

Fisher, B., \& Rogal, L. (1986). Eye-hand coordination in man: A latency study. Biological Cybernetics, 55, 253-261.

FISK, J. D., \& GoODALE, M. A. (1989). The effects of instructions to subjects on the programming of visually directed reaching movements. Journal of Motor Behavior, 21, 5-19.

FLEISHER, A. G. (1989). Planning and execution of hand movements. Biological Cybernetics, 60, 311-321.

Georgopoulos, A. P., MAssey, J. T. (1987). Cognitive spatial-motor processes: 1 . The making of movements at various angles from a stimulus direction. Experimental Brain Research, 65, 361-370.

Gonshor, A., \& Melvill-Jones, G. (1976). Extreme vestibulo-ocular adaptation induced by prolonged optical reversal of vision. Journal of Physiology, 256, 381-414.

Hardt, M. E., Held, R., \& Steinbach, M. J. (1971). Adaptation to displaced vision: A change in the central control of sensorimotor coordination. Journal of Experimental Psychology, 89, 229-239.

HaRris, C. S. (1963). Adaptation to displaced vision: Visual, motor, or proprioceptive change? Science, 140, 812-813.

HARRIS, C. S. (1965). Perceptual adaptation to inverted, reversed, and displaced vision. Psychological Review, 72, 419-444.

HeLD, R. (1961). Exposure history as a factor in maintaining stability of perception and coordination. Journal of Nervous \& Mental Disease, 132, 26-32.

JacoBson, L. S., \& Goodale, M. A. (1989). Trajectories of reaches to prismatically displaced targets: Evidence for "automatic" visuomotor recalibration. Experimental Brain Research, 78, 575-587.

JEANNEROD, M. (1988). The neural and behavioural organization of goal directed movements. Oxford Psychology Series 15, 283.

JEANNEROD, M. (1991). The interaction of visual and proprioceptive cues in controlling reaching movements. In D. R. Humphrey \& H.-J. Freund (Eds.), Motor control: Concepts and issues (pp. 277291). New York: Wiley.

Kinlstrom, J. F., Barnhardt, T. M., \& TATARyn, D. J. (1992). Implicit perception. In R. F. Bornstein \& T. S. Pittman (Eds.) Perception without awareness: Cognitive, clinical and social perspectives (pp. 17-54). New York: Guilford.

KoGA, K. (1988). Methods for transforming the human vision. In T. Mori (Ed.), Disorganization and reconstruction of the visual world under altered vision (pp. 245-273). Nagoya: Chukyo Daigaku.
KOHLER, I. (1955). Experiments with prolonged optical distortion. Acta Psychologica, 11, 176-178.

KOHLER, I. (1962). Experiments with goggles. Scientific American, 206, 62-86.

KoHLER, I. (1964). The formation and transformation of the perceptual world. Psychological Issues, 3, 1-166.

KORNHEISER, A. S. (1976). Adaptation to laterally displaced vision: A review. Psychological Bulletin, 83, 783-816

Melamed, L. E., Beckett, P. A., Wallace, B. (1978). The effect of prism strength and response mode on the magnitude of the correction effect in prism viewing. Perception \& Psychophysics, 23, 176-180.

Melvill-Jones, G., Guitton, D., \& Berthoz, A. (1988). Changing patterns of eye-head coordination during $6 \mathrm{~h}$ of optically reversed vision. Experimental Brain Research, 69, 531-544.

Prablanc, C., Echallier, J. F., Jeannerod, M., \& Komilis, E. (1979a). Optimal response of eye and hand motor systems in pointing at a visual target: 1. Spatio-temporal characteristics of eye and hand movements and their relationships when varying the amount of visual information. Biological Cybernetics, 35, 113-124.

Prablanc, C., Echallier, J. F., Komilis, E., \& Jeannerod, $M$. (1979b). Optimal response of eye and hand motor systems in pointing at a visual target: 2 . Static and dynamic visual cues in the control of hand movements. Biological Cybernetics, 35, 183-187.

Prablanc, C., Pelisson, D., \& Goodale, E. M. A. (1986). Visual control of reaching movements without vision of the limb: 1 . Role of retinal feedback of target position in guiding the hand. Experimental Brain Research, 62, 293-302.

Putterman, A., Robert, A., \& Bregman, A. (1969). Adaptation of the wrist to displacing prisms. Psychonomic Science, 16, 79-80.

Redding, G. M., \& Wallace, B. (1978). Sources of overadditivity in prism adaptation. Perception \& Psychophysics, 24, 58-62.

Redding, G. M., \& Wallace, B. (1988). Components of prism adaptation in terminal and concurrent exposure: Organization of eye-hand coordination loop. Perception \& Psychophysics, 44, 59-68.

Redding, G. M., \& WAllace, B. (1992). Adaptative eye-hand coordination: Implications of prism adaptation for perceptual-motor organization. In L. Proteau \& D. Elliott (Eds.), Vision and motor control (pp. 105-127). Amsterdam: Elsevier.

Rock, I., GoldberG, J., \& MACK, A. (1966). Immediate correction and adaptation based on viewing a prismatically displaced scene. Perception \& Psychophysics, 1, 351-354.

Rossetti, Y., Koga, K., Susami, K., \& Mano, T. (1991). Eye-head coordination during wedge prism adaptation. Annals of the Research Institute of Environmental Medicine, 42, 241-245.

ShEPARD, R. N., \& METZler, J. (1971). Mental rotation of threedimensional objects. Science, 171, 701-703.

SNedecor, G. W., \& Cochran, W. G. (1984). Statistical methods (6th ed.; H. Boelle \& E. Camhaji, Trans.) Paris: A.C.T.A.

TASHIRO, T. (1972). Adaptation processes in transformed vision: Approach from finger pointing reaction time analysis. Annual Report of Osaka City University, 23, 86-97.

Templeton, W., Howard, I., \& Wilkinson, D. (1974). Additivity of components of prismatic adaptation. Perception \& Psychophysics, 15, 249-257.

Vercher, J. L., Prablanc, C., Magenes, G., \& Gauthier, G. M. (1992). Coordination des mouvements des yeux, de la main et de la tête dans une tâche de pointage. In M. Laurent, J.-F. Marini, R. Pfister, \& P. Therme (Eds.), Recherches en A.P.S.: 3. Activités motrices (pp. 49-58). Paris: Actio.

Wallace, B., Melamed, L. E., \& CoHen, R. R. (1973). An analysis of aftereffects in the measurement of the correction effect. Perception \& Psychophysics, 14, 21-23.

Wallace, B., \& REDDING, G. M. (1979). Additivity in prism adaptation as manifested in intermanual and interocular transfer. Perception \& Psychophysics, 25, 133-136.

Weiner, M. J., Hallett, M., \& Funkenstein, H. H. (1983). Adaptation to lateral displacement of vision in patients with lesions of the central nervous system. Neurology, 33, 766-772. 
WELCH, R. B. (1986). Adaptation of space perception. In K. R. Boff, L. Kaufman, \& J. P. Thomas (Eds.), Handbook of perception and human performance: Sensory processes and perception (Vol. 1, pp. 24.1-24.45). New York: Wiley.

Welch, R. B., Choe, C. S., \& Heinrich, D. R. (1974). Evidence for a three-component model of prism adaptation. Journal of Experimental Psychology, 103, 700-705.

WeLCH, R. B., \& Goldstein, G. D. (1972). Prism adaptation and brain damage. Neuropsychologia, 10, 387-394.

WELCH, R., B., \& WARREN, D. H. (1980). Immediate perceptual response to intersensory discrepancy. Psychological Bulletin, 83, 638-667.

Welch, R. B., Widawski, M. H., Harrington, J., \& Warren, D. H.
(1979). An examination of the relationship between visual capture and prism adaptation. Perception \& Psychophysics, 25, 126-132. WiLKINSON, D. A. (1971). Visual-motor loop: A linear system? Journal of Experimental Psychology, 89, 250-257.

\section{NOTE}

1. Preliminary results of this work were presented by Rossetti, Koga, Susami, and Mano (1991).

(Manuscript received December 16, 1991; revision accepted for publication February 11, 1993.)

\section{4th Annual Meeting of the Psychonomic Society Washington, DC November 5, 6, and 7, 1993}

The 34th Annual Meeting of the Psychonomic Society will be held in Washington, DC, November 5 , 6, and 7, 1993, at the Omni Shoreham Hotel. The meetings will begin Friday morning and continue until Sunday at noon.

The program and hotel reservation cards will be mailed to members and associates early in September. A copy of the program will be published in the Bulletin of the Psychonomic Society. Additional programs will be available at the registration desk for $\$ 7.00$.

For further information, please contact the Secretary-Treasurer of the Society: Randi C. Martin, Department of Psychology, Rice University, P.O. Box 1892, Houston, TX 77251-1892 (phone: 713-527-8101, ext. 3417; e-mail: rmartina@riceVM1.rice.edu). 